\title{
Pengaruh Konfigurasi Tabung Kompresor Terhadap Unjuk Kerja Pompa Hidram
}

\author{
Didin S. Fane ${ }^{\star}$, Rudy Sutanto**, I Made Mara** \\ Jurusan Teknik Mesin, Fakultas Teknik, Universitas Mataram \\ Jalan Majapahit No.62 Mataram
}

\begin{abstract}
A hydraulic ram pump is a cyclic water pump powered by hydropower. It functions as a hydraulic transformer that takes in water at one pressure and flow rate, and outputs water at a higher hydraulic head and lower flow rate. Hydraulic ram pump uses the water hammer effect to develop pressure that allows a portion of the input water that powers the pump to be lifted to a point higher than where the water originally started. The hydraulic ram pump is used in remote areas, where there is both a source of low-head hydropower and a need for pumping water to a destination higher in elevation than the source.

In this research using tube compressor with 3-inch tube diameter and height 25 centimeters. Level of water used is at position 5 meters with 8 meters height of calculate the output discharge. The observed parameters are input pressure, output pressure, the tube compressors pressure; valves waste pressure, water discharge input, output water flow and pump efficiency.

The result showed that hydram pump ILK position, with parallel compressor tube configuration have better performance than the configuration of compressor tube series. Which the maximum head 22 meters is achieved. And discharge result at the height calculated (8 meters) of 0.0453 liters / sec and $3.278 \%$ efficiency.
\end{abstract}

Keyword : hidram pump, tube compressor, serial, parallel.

\section{Latar Belakang}

Air merupakan kebutuhan yang sangat penting bagi manusia, hewan dan tumbuh-tumbuhan. Kebutuhan air yang cukup banyak seringkali menimbulkan permasalahan baru bagi manusia, khususnya bagi masyarakat yang tinggal jauh dari sumber air atau berada di tempat yang berada diatas sumber air. Masyarakat biasa menggunakan pompa air untuk memompakan air dari sumber air ke tempat tinggal mereka. Penggunaan pompa air ini juga masih mengalami kesulitan, antara lain tidak tersedianya sumber tenaga listrik atau sulitnya mendapatkan bahan bakar dan mahalnya biaya operasional pompa.

Sehingga pompa hidraulik ram dinilai cukup tepat untuk mengatasi permasalahan tersebut, sebab mempunyai beberapa keuntungan jika dibandingkan dengan jenis pompa yang lain, yaitu tidak membutuhkan energi listrik atau bahan bakar, tidak membutuhkan pelumasan, biaya pembuatan dan pemeliharaannya relatif murah dan pembuatannnya cukup mudah. Penelitian lain tentang berbagai rancangan dan unjuk kerja pompa hidram telah dilakukan, pada pompa hidram, terdapat satu komponen penting, yaitu tabung kompresor. Disamping untuk mendapatkan aliran pemompaan yang kontinu, tabung kompresor juga berfungsi mengurangi daya yang dibutuhkan pada pompa untuk menaikkan air.

\section{Dasar Teori \\ 2.1 Pompa Hidram}

Pompa hidram atau singkatan dari hidraulic ram berasal dari kata hidro $=$ air (cairan), dan ram = hantaman, pukulan atau tekanan, sehingga terjemahan bebasnya menjadi tekanan air. Jadi pompa hydram adalah sebuah pompa yang energi atau tenaga penggeraknya berasal dari tekanan atau hantaman air yang masuk kedalam pompa melalui pipa. Masuknya air yang berasal dari berbagai sumber air ke dalam pompa harus berjalan secara kontinyu atau terus menerus. Alat ini sederhana dan efektif digunakan pada kondisi yang sesuai dengan syarat-syarat yang diperlukan untuk operasinya. Dalam kerjanya alat ini, tekanan dinamik yang ditimbulkan memungkinkan air mengalir dari tinggi vertical (head) yang rendah ke tempat yang lebih tinggi. Penggunaan hidraulik ram tidak terbatas hanya pada penyediaan air untuk kebutuhan rumah tangga, tapi juga dapat digunakan untuk pertanian, peternakan, dan perikanan darat. Karena pompa ini bekerja tanpa menggunakan bahan bakar minyak (BBM) atau tanpa motor listrik maka disebut juga " 
Pompa Air Tanpa Motor " ( Motorless Water Pump ) dan disingkat PATM

\subsection{Palu Air (Water hammer)}

Gejala palu air terjadi karena adanya air dari reservoir dialirkan melalui pipa secara tiba-tiba dihentikan oleh suatu penutupan katup, maka energi potensial akan berubah menjadi energi kinetik, sehingga serangkaian gelombang tekanan positif dan negatif akan bergerak maju mundur di dalam pipa sampai terhenti akibat gesekan.

Pompa hidram bekerja berdasarkan palu air, ketika suatu aliran fluida dalam pipa dihentikan secara tiba-tiba misalnya dengan menutup katup dengan sangat cepat, sehingga akan membentur katup dan menimbulkan tekanan yang melonjak disertai fluktuasi tekanan di sepanjang pipa untuk beberapa saat.

Sebagian gelombang tekanan tersebut akan menjadi arus balik ke arah reservoir dan ini berarti terjadi penurunan tekanan pada sistem pompa sehingga klep penghantar tertutup kembali sedangkan klep limbah membuka kembali. Akibat dari pembebasan gelombang tekanan tersebut kembali lagi arus massa air dari reservoir menuju pompa akan menekan naik klep limbah sehingga terjadi penutupan tiba-tiba yang mengakibatkan terjadi proses palu air. Proses yang terjadi berulang-ulang inilah yang mendorong naik air ke pipa penghantar untuk kemudian diteruskan ke bak penampung.

\subsection{Efisiensi pompa hidram}

$$
\eta=\frac{Q_{2}}{Q_{1}} \times \frac{H_{2}}{H_{1}}
$$

Dimana:

$\eta=$ efisiensi pompa hydram

$\mathrm{Q}_{1}=$ Debit air terjunan atau input (1/menit)

$\mathrm{Q}_{2}=$ Debit air yang dinaikkan atau output ( $/ /$ menit)

$\mathrm{H}_{1}=$ Tinggi terjunan air atau input $(\mathrm{m})$

$\mathrm{H}_{2}=$ Tinggi air angkat atau output $(\mathrm{m})$

\section{Metode Penelitian}

\subsection{Rancangan Penelitian}

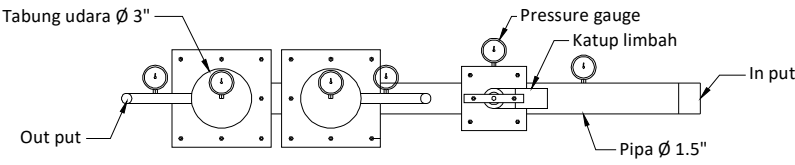

Gambar 1. Pompa Hidram dengan konfigurasi tabung kompresor seri

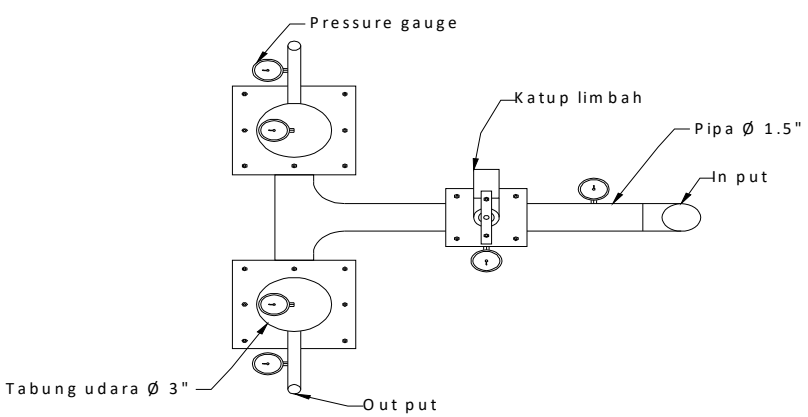

Gambar 2. Pompa Hidram dengan Konfigurasi Tabung Kompresor Paralel

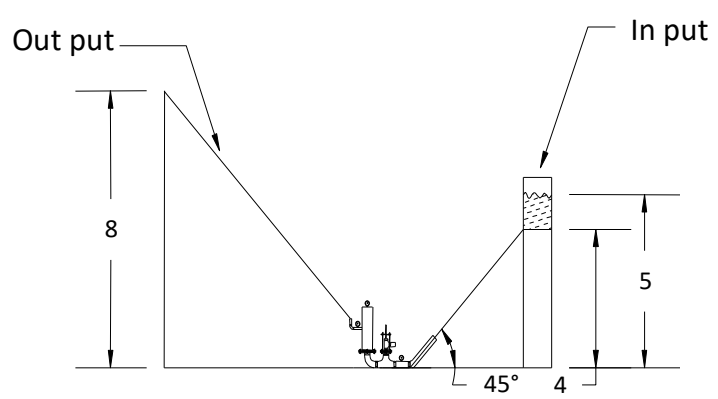

Gambar 3. Instalasi Pengujian Pompa Hidram

Penelitian ini bertujuan untuk mengetahui pengaruh konfigurasi tabung kompresor seri dan paralel pada pompa hidram susunan ILK terhadap unjuk kerjanya. Berikut parameter kerja yang diamati :
a. Tekanan input
b. Tekanan output
c. Tekanan tabung kompresor
d. Tekanan katup limbah
e. Debit air input
f. Debit air output
g. Efisiensi pompa

\subsection{Tahap Pengujian}

a. Mengatur tinggi terjunan, dan sudut terjunan sesuai dengan perlakuan yang diberikan.

b. Menghubungkan sumber air ke pompa dengan menggunakan pipa yang telah disiapkan.

c. Mengalirkan air dari sumber air ( bak air ) ke pompa yang telah dipasang.

d. Mengukur tekanan input, tekanan output, tekanan tabung kompresi, debit air input, dan debit air output.

e. Pengujian tersebut diulangi pada masing-masing variabel. 


\section{Hasil dan Pembahasan}

\subsection{Data Hasil Pengujian}

Dalam penelitian ini dilakukan pengujian pompa hidram dengan menggunakan variasi konfigurasi tabung kompresor seri dan paralel dengan susunan pompa ILK. Adapun instalasi pompa :

1. Diameter rumah pompa 1,5 inci

2. Pipa input 1,5 inci

3. Pipa output 0,5 inci

4. Tabung yang digunakan dua buah, dengan dimensi masing-masing :

- Tinggi $25 \mathrm{Cm}$

- Diameter 3 inci.

5. Tinggi level air 5 meter.

Sedangkan proses pengambilan data dilakukan dengan tiga kali pengulangan untuk setiap variasi yang diuji.

Berdasarkan hasil penelitian dilapangan diperoleh data untuk tekanan input, tekanan output, tekanan tabung kompresor, tekanan katup limbah, debit input, debit output dan head maksimum pompa.

Unjuk kerja pompa yang akan yang dianalisa pada penelitian ini adalah debit air output pada ketinggian $8 \mathrm{~m}$, head maksimum pompa, dan efisiensi pompa.

Tabel 1 adalah data hasil penelitian yang telah dilakukan untuk masing-masing variasi.

Tabel 1. Data performance pompa hidram.

\begin{tabular}{|c|c|c|c|}
\hline No & $\begin{array}{l}\text { Variabel yang diamati (rata- } \\
\text { rata) }\end{array}$ & Seri & Paralel \\
\hline 1 & Tekanan input $\left(\mathrm{P}_{\text {in }}\right)\left(\mathrm{kg} / \mathrm{cm}^{2}\right)$ & 1,25 & 1,6 \\
\hline 2 & $\begin{array}{l}\text { Tekanan katup limbah }\left(\mathrm{P}_{\text {limbah }}\right) \\
\left(\mathrm{kg} / \mathrm{cm}^{2}\right)\end{array}$ & 1 & 1,4 \\
\hline 3 & $\begin{array}{l}\text { Tekanan tabung kompresor } 1 \\
\left(\mathrm{P}_{\mathrm{k} 1}\right)\left(\mathrm{kg} / \mathrm{cm}^{2}\right)\end{array}$ & 1 & 1 \\
\hline 4 & $\begin{array}{l}\text { Tekanan tabung kompresor } 2 \\
\left(\mathrm{P}_{\mathrm{k} 2}\right)\left(\mathrm{kg} / \mathrm{cm}^{2}\right)\end{array}$ & 1 & 1 \\
\hline 5 & $\begin{array}{l}\text { Tekanan output kompresor } 1 \\
\left(\mathrm{P}_{\text {out } 1}\right)\left(\mathrm{kg} / \mathrm{cm}^{2}\right)\end{array}$ & 0,8 & 0,8 \\
\hline 6 & $\begin{array}{l}\text { Tekanan output kompresor } 2 \\
\left(\mathrm{P}_{\text {out } 2}\right)\left(\mathrm{kg} / \mathrm{cm}^{2}\right)\end{array}$ & 0,8 & 0,8 \\
\hline 7 & Debit air input (liter/detik) & 2,211 & 2,211 \\
\hline 8 & $\begin{array}{l}\text { Debit air output pada } \\
\text { ketinggian } 8 \mathrm{~m} \text { (liter/detik) }\end{array}$ & 0,038023 & 0,0453 \\
\hline 9 & Head maksimum (m) & 16 & 22 \\
\hline
\end{tabular}

\subsubsection{Head Maksimum}

Head maksimum terbesar yang diperoleh dari pengujian pada pompa hidram dengan kofigurasi tabung kompresor seri dan pompa hidram dengan konfigurasi tabung kompresor paralel diperoleh pada pompa hidram dengan konfigurasi tabung kompresor paralel.
Hal ini terjadi akibat gaya pada air yang terdorong masuk ke dalam tabung kompresor tersebut akan menekan udara yang ada di dalam tabung ke segala arah, sehingga volume udara yang ada di dalam tabung kompresor akan mengecil sedangkan tekanannya akan membesar. Hal ini sesuai dengan hukum Pascal yang berbunyi "Jika permukaan zat cair yang berada pada suatu ruang tertutup diberikan tekanan, maka tekanan tersebut akan diteruskan ke segala arah dengan sama besar".

Pada kasus pompa hidram dengan konfigurasi tabung seri dan pompa hidram dengan konfigurasi tabung paralel, hal ini berkaitan dengan efek water hammer atau tekanan balik air yang mengakibatkan tekanan yang cukup besar di dalam badan pompa saat tabung kompresor terisi penuh.

Jika dibandingkan dengan pompa hidram konfigurasi tabung seri, pada pompa hidram dengan konfigurasi tabung kompresor paralel, gelombang energi yang terjadi akibat efek water hammer langsung menuju masuk ke dalam kedua tabung kompresor secara bersamaan dan sama besar, sedangkan pada pompa hidram dengan konfigurasi tabung kompresor seri, di mana gelombang energi yang terjadi akibat efek water hammer memasuki tabung kompresor pertama sebelum memasuki tabung kompresor yang kedua.

Hal ini terjadi karena pada pompa hidram dengan konfigurasi seri, ada beda jarak antara tabung kompresor satu dengan yang lainnya terhadap katup limbah, yang menyebabkan adanya reduksi energi untuk masuk ke dalam tabung yang terjauh dari katup limbah.

Hal tersebut yang mempengaruhi kecepatan denyutan katup limbah, dimana pada pengujian pompa hidram dengan konfigurasi tabung paralel denyutan katup limbah lebih cepat dibanding pada pengujian pompa hidram dengan konfigurasi tabung seri. Dan hal ini juga yang mempengaruhi debit yang dapat diangkat oleh pompa hidram.

Head maksimum yang dihasilkan pada pengujian pompa hidram dengan konfigurasi tabung kompresor seri danpompa hidram dengan konfigurasi tabung kompresor paralel sangat dipengaruhi oleh kecepatan denyutan dari katup limbah, yang juga mempengaruhi debit keluaran pada head hitung yang sama(8meter), seperti pada tabel 1.

Dengan kata lain, jarak dari katup limbah dan tabung kompresor mempengaruhi 
jumlah denyutan katup limbah, sedangkan denyutan katup limbah mempengaruhi head dan debit dari pengujian pompa hidram dengan konfigurasi tabung kompresor seri dan pompa hidram dengan konfigurasi tabung kompresor paaralel.

Dari data di atas dapat dibuat grafik perbandingan head antara pompa hidram konfigurasi tabung seri dengan pompa hidram konfigurasi tabung paralel.

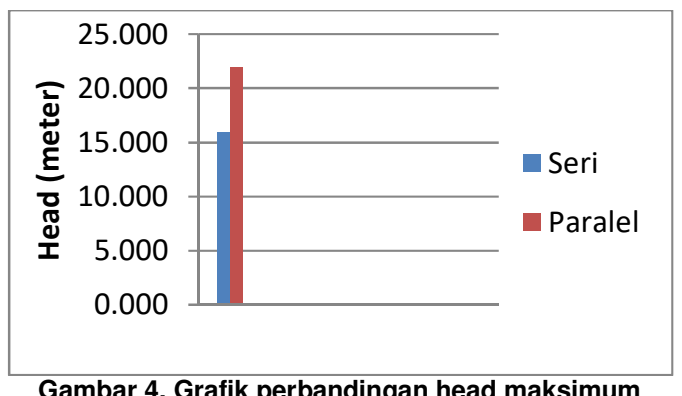

\subsubsection{Debit}

Berikut adalah grafik perbandingan debit output antara pompa hidram konfigurasi tabung kompresor seri dan pompa hidram dengan konfigurasi tabung paralel pada ketinggian 8 meter.

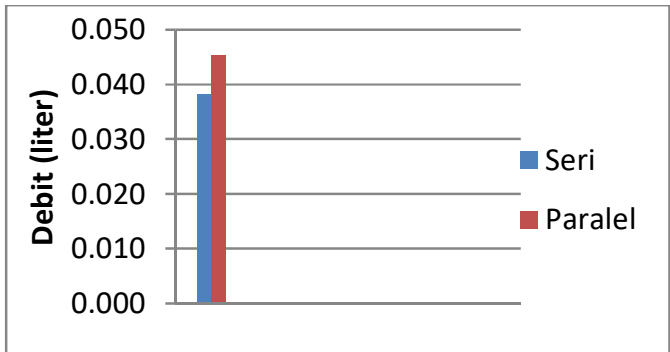

Gambar 5. Grafik perbandingan Debit output pada ketinggian 8 meter

Dari grafik di atas diketahui bahwa debit pada pompa hidram konfigurasi paralel lebih tinggi dibandingkan dengan pompa hidram dengan konfigurasi seri. Hal ini disebabkan masing-masing tabung pada pompa hidram dengan konfigurasi paralel, air memasuki tabung secara bersamaan, dengan jumlah yang relatif sama dibandingkan dengan pompa hidram konfigurasi tabung seri. Di mana air yang mengalir memasuki tabung kompresor pertama terlebih dahulu sebelum memasuki tabung kompresor kedua.

$\mathrm{Hal}$ ini terjadi akibat gelombang energi yang terjadi akibat efek water hammer langsung masuk ke dalam kedua tabung kompresor secara bersamaan dan sama besar pada pompa hidram dengan konfigurasi tabung kompresor paralel. Sedangkan pada pompa hidram dengan konfigurasi tabung kompresor seri, dimana gelombang energi yang terjadi akibat efek water hammer memasuki tabung kompresor pertama sebelum memasuki tabung kompresor yang kedua.

Hal ini terjadi karena pada pompa hidram dengan konfigurasi seri, ada beda jarak antara tabung kompresor satu dengan yang lainnya, yang menyebabkan adanya pengurangan energi yang masuk ke dalam tabung berikutnya.

\subsubsection{Efisiensi}

Efisiensi diperoleh dari perbandingan debit output dan debit input dikalikan dengan perbandingan head output dan head sumber air.

didapat :

Berdasarkan data di atas maka Efisiensi rata-rata pompa dengan konfigurasi seri (\%) :

$$
\begin{aligned}
& \eta=\frac{0,038023}{2,211} \times \frac{8}{5} \times 100 \% \\
& \eta=2,809 \% .
\end{aligned}
$$

Sedangkan Efisiensi pompa rata-rata dengan konfigurasi paralel (\%):

$$
\begin{aligned}
& \eta=\frac{0,0453}{2,211} \times \frac{8}{5} \times 100 \% \\
& \eta=3,278 \% .
\end{aligned}
$$

Berdasarkan hasil pengolahan data pengujian pompa hidram dengan konfigurasi tabung kompresor seri dan pompa hidram dengan konfigurasi tabung kompresor paralel pada ketinggian 8 meter, dapat dibuat grafik perbandingan efisiensi pompa hidram dengan konfigurasi tabung kompresor seri dan pompa hidram dengan konfigurasi tabung kompresor paralel.

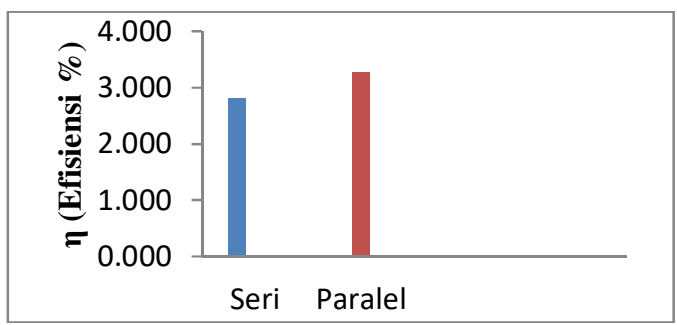

Gambar 6. Grafik perbandingan efisiensi

Efisiensi pompa selalu berbanding lurus dengan debit output dan head pompa. Berdasarkan data pada grafik diatas efisiensi pompa terbesar dihasilkan pada variasi pompa hidram konfigurasi tabung paralel, hal ini disebabkan karena pada variasi ini kapasitas pemompaan dan head 
maksimalnya paling besar sehingga efesiensi yang dihasilkan juga besar.

\section{Dartar Pustaka}

ACF, 2009, Design, Sizing, Construction, And Maintenance Or Gravity-Fed System In Rural Area, Paris, Action Contre la Faim (ACF).

Anonim, 2006. Pumps and Pumping Systems. www.energyefficiencyasia.org (di unduh pada hari Minggu 19 Desember 2010)

Anonim, 2010, Pembuatan Pompa Hidraulik Ram. Pada http :khatulistiwa.info/.../11 pembuatan-pompa-hidraulik-ram-.html (di unduh pada hari Kamis 16 Desember 2010)

Balitbang PU, 2005, Penjelasan Teknologi Pompa Hidram, PT Medias, Jakarta. Yayasan Penerbit PU

Bjarnegard, F., 2004, Ram Pump and Solar Pump Training, Border Green Energy Team, dalam www.bget.org (di unduh pada hari Minggu 19 Desember 2010)

Hanafie J. dan Longh H.D., 1979. Teknologi Pompa Hidraulik Ram. Bandung, Institut Teknologi Bandung.

Jaelani, A., 2011, Pengaruh Pemakaian Variasi Tinggi Serta Posisi Pemasangan Tabung Kompresor Terhadap Unjuk Kerja Pompa Hidram (Hidraulic Ram). Skripsi Universitas Mataram, Mataram.
Linsey, R.K and Francini, J.B., 1979. Water Resources Engineering. McGraw-Hill, New York.

Putra, T., 2010. Pengujian Pompa Hidram Sebagai Pompa Ramah Lingkungan. Skripsi , Universitas Mataram, Mataram.

Rochmanhadi, 2000, Alat Uji Laboratorium, Medias, Yayasan Penerbit PU, Jakarta.

Suarda, M. dan Wirawan, IKG., 2008, Kajian Eksperimental Pengaruh Tabung Udara Pada Head Tekanan Pompa Hidram, Bali. Unud. Pada http: ejournal.unud.ac.id (di unduh pada hari Senin 27 Desember 2010)

Tessema, A.W, 2000, Hydraulic Ram System Design and Application, ESME.

Wahyudi, S. I dan Fachrudin, F.,2008, Korelasi Tekanan dan Debit Air Pompa Hidram Sebagai Teknologi Pompa Tanpa Bahan Bakar Minyak, Jurusan Teknik Sipil, Fakultas Teknik, UNISSULA, Semarang.

Widarto L dan Sudarto,F.X. 1997, Membuat Pompa Hidram, Penerbit Kanisius, Yogyakarta. 